\begin{tabular}{|l|c|c|c|r|}
\hline $\begin{array}{l}\text { Cuadernos de Investigación Geográfica } \\
\text { Geographical Research Letters }\end{array}$ & 2018 & N $^{\circ} 44(2)$ & pp. 697-718 & $\begin{array}{r}\text { ISSN 0211-6820 } \\
\text { eISSN 1697-9540 }\end{array}$ \\
\hline
\end{tabular}

\title{
EFFECTS OF THE TEXTURE AND ORGANIC MATTER VALUES IN THE ESTIMATION OF THE SOIL WATER CONTENT AT A REGIONAL SCALE
}

\author{
P. PÉREZ-CUTILLAS ${ }^{1,2}$, G.G. BARBERÁ ${ }^{2}$, C. CONESA-GARCÍA ${ }^{1 *}$ \\ 'Departamento de Geografía, Universidad de Murcia, Campus de la Merced, s/n, 30001 Murcia, Spain. \\ ${ }^{2}$ Grupo de Erosión y Conservación de Suelos, Centro de Edafología y Biología Aplicada del Segura, \\ Consejo Superior de Investigaciones Científicas (CEBAS-CSIC), Campus de Espinardo, \\ 30100 Murcia, Spain.
}

\begin{abstract}
This study compares two methods for the estimation of hydraulic properties of the soil at the regional scale. Soil water content $(\theta)$ values were estimated at two fixed soil matric potential values, associated with the field capacity $(\theta f c)$ and wilting point $(\theta w p)$. The first method is carried out directly using $(\theta)$ values of analytical determinations, by modeling them as a function of environmental variables. The second method employed texture and organic matter (OM) information to obtain $(\theta)$ values by pedotransfer functions (PTFs). The comparison of both methods allows evaluating the effect of the textures and $O M$, of which a significant effect of these variables is produced, suggested that there is a considerable level of consistency between the two methods, despite some differences induced by coarse textures (sand) and OM.

Efectos de la textura y la materia orgánica en la estimación del contenido de agua en el suelo a escala regional
\end{abstract}

RESUMEN. Se plantea el estudio de dos métodos para la estimación de propiedades hidráulicas del suelo a escala regional, a partir de la estimación del valor del contenido de agua del suelo $(\theta)$ en dos valores de potencial de suelo, asociados con la capacidad de campo $\left(\theta_{f_{c}}\right)$ y punto de marchitez $\left(\theta_{w p}\right)$. Un primer método se efectúa de forma directa a partir de los valores de $(\theta)$ de determinaciones analíticas mediante su modelización como función de las variables ambientales. Y una segunda estimación, realizada a partir de valores de textura y materia orgánica $(M O)$, para obtener mediante funciones de edafotransferencia (PTFs) valores de $(\theta)$. El estudio comparativo permite a su vez evaluar el efecto de las texturas y MO en ambos métodos a través sus diferencias. La comparación de ambos métodos permite evaluar su relación con las texturas y $\mathrm{MO}$, del que se detecta un efecto significativo de estas variables. Por otra parte, los resultados obtenidos sugieren que existe un nivel considerable de consistencia entre los dos métodos, a pesar de algunas diferencias inducidas en mayor medida por las texturas más gruesas (arena) y OM. 
Key words: soil moisture retention curve, pedotransfer functions, GIS SE Spain.

Palabras clave: suelo, propiedades hídricas, funciones de edafotrasferencia, SIG, Sureste de España.

Received: 23 November 2017

Accepted: 13 December 2017

* Corresponding author: Carmelo Conesa-García, Departamento de Geografía, Universidad de Murcia, Campus de la Merced s/n, 30001 Murcia, Spain. E-mail address: cconesa@um.es

\section{Introduction}

The measurement of soil water properties, both in the field and in the laboratory, is complex in time and resources, in addition to demanding a large number of samples due to the spatial variability of the soil (Klute, 1986). A good solution is the prediction of these properties through the use of pedotransfer functions. These functions, based on empirical relationships, make it possible to predict the hydraulic properties of a soil, based on other, more easily measurable variables, such as the texture and organic matter (OM) content of soils (Van Genuchten, 1980). In general, both properties play a dominant role in any estimation of the hydraulic properties of the soil (Patil and Singh, 2016); therefore, to obtain regional estimates of these characteristics, a spatially distributed determination of texture and OM is essential.

Knowledge of the relationships between the matric potential and water content processes is vital to describe the hydrodynamic properties of the soil. The soil water content is usually regulated by the capacity of each soil for retaining water at a certain negative pressure, so that the availability of water will be determined by the relationship of these processes, together with the previous moisture content in the hydrological systems under study (Malik et al., 1987). Given the difficulty and cost of direct measurements, many indirect methods have been developed to estimate the hydraulic characteristics from soil variables that are easier to measure. To define this approach or procedure, Bouma (1989) coined the term Pedotransfer Function (PTF).

Soil organic matter (SOM) conditions substantially the basic properties of soils and, particularly, important hydrological and geomorphological functions, since it favors the aggregation of the soil. It allows the formation of clay-humic complexes which act as the core of soil aggregates (Lal et al., 1994), increasing their porosity and, thus, the infiltration and percolation of fluids. Consequently, it increases the water retention capacity of the soil (Brady, 1984), while the risk of run-off and erosion decreases (Van Beers, 1980). Texture is one of the most important variables in the control of the hydraulic properties of the soil; hence, its characteristics reflect the size grain, porosity and absorption of water in soil particles (Rawls et al., 1982, Schaap et al., 2001; Rawls et al., 2003; Santanello et al., 2007). 
Some of the important turning points in the evolution of these works occurred with the appearance of the ROSETTA computer program (Schaap et al., 2001). It is an application designed to estimate the hydraulic parameters of the soil through hierarchical pedotransfer functions, both in saturated and unsaturated soils. Several studies (Šimùnek et al., 2008; Børgesen et al., 2008; Kreye and Meon, 2016) have calibrated and tested this method using different sets of predictors and the parameters obtained by van Genuchten/ Mualem methods.

In other work, there has been analysis of lazy learning methods to estimate hydraulic properties. One type of "Lazy Learning" is the K Nearest Neighbors (k-NN) method (Wettschereck et al., 1997). Using this approach, a study was carried out (Nemes et al., 2006) based on information on OM, bulk density and texture of the soil, in order to test the classification method on the analysis of neural networks (NNet). These k-NN techniques are now postulated as a competitive alternative to other techniques for the development of PTF functions, due to development of the PTF have made it unnecessary to have a large amount of data. In short, all these analyses are based on predictive functions that translate, by means of statistical algorithms, the physical and/or chemical properties of the soil, which are easier to obtain, into hydraulic properties, which require more complex and expensive determination (Bouma, 1989).

Several studies recognize the usefulness of predictive regression models to obtain hydraulic functions of the soil properties at large scales (Wosten and Van Genuchten, 1988; Schuh and Cline, 1990; Twarakavi et al., 2010). However, there are few works referring to the analysis and application of techniques that, based on the use of statistical models, try to estimate the hydraulic properties of the soil at a regional scale through environmental variables. The calculation processes developed in these studies allow to obtain spatial results relate environmental characteristics, at the same level as other direct estimation techniques generated through interpolation methods, such as cokriging, or geographically weighted regression (GWR) processes (Wang et al., 2013).

In this study, the exploration of procedures for the estimation of soil water content at a regional scale has been proposed, for this purpose two calculations of the soil water potential have been made. A first calculation is made directly from the $\theta$ values of the soil analytical determinations carried out in the LUCDEME project (ICONA 1996) through their modeling as a function of the environmental variables. A second estimate has been made using information on texture and OM and PTFs. The comparative study of these two methods allows us to analyze the differences between a direct estimation procedure that uses a reduced number of data with empirical soil moisture values, and a second method based on an indirect estimation from a larger number of sampled values.

\section{Material and methods}

\subsection{Study area and sources of information}

The study area, located in the SE of the Iberian Peninsula, corresponds to the territory of the Region of Murcia that lies within the Segura River Basin, an area of approximately 1,100,000 hectares (Fig. 1). The information used in this study extracted 
from the LUCDEME project, in which the processes of desertification in arid and semiarid zones in Spain have been analyzed. Focuses on the complete data of a selection of 557 soil profiles, sampled ad-hoc and distributed throughout the territory in the places where these profiles are best represented (Fig. 1). The information of the profiles is classified according to the depths of the different horizons observed in the field, and based on their physico-chemical properties, resulting in 1880 records.

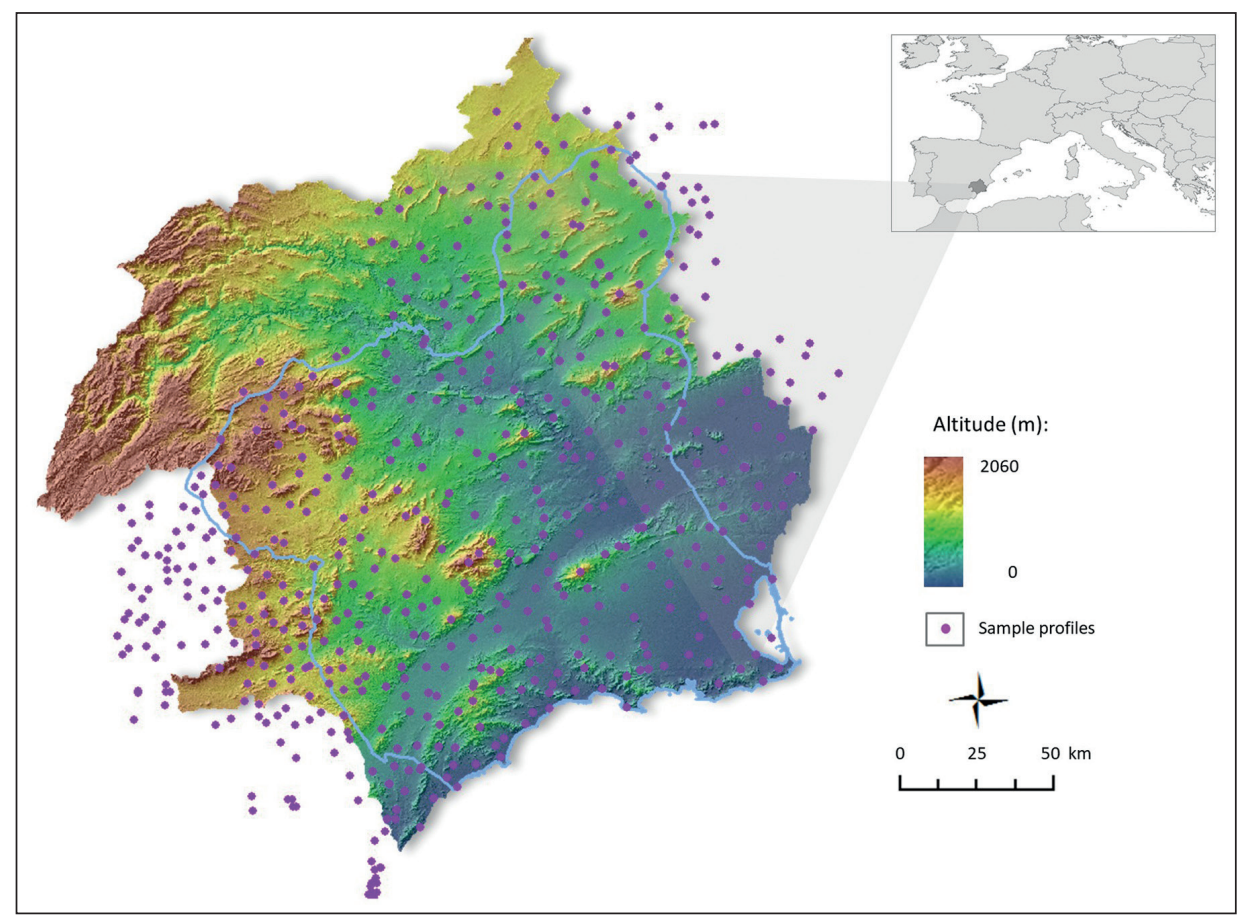

Figure 1. The Segura river basin, in the SE of the Iberian Peninsula. The pale blue shows the limits of the Region of Murcia. The magnet points indicate the distribution of the soil profiles sampled within the LUDEME project framework Spatial distribution of the field samplings (magenta points) of the LUCDEME project for the determinations of the profiles.

\subsection{Methods}

The methodology followed in this study is based on the comparative analysis of two procedures for obtaining values of soil water properties at a regional level. In particular, it is intended to determine the soil water content $(\theta)$, associated with the field capacity $\left(\theta_{\mathrm{fc}}\right)$ and wilting point $\left(\theta_{\mathrm{wp}}\right)$ (Richards and Weaver, 1944), corresponds to the matric potential values of 2.5 and 4.2 for the soil state at $\theta_{\mathrm{fc}}$ and $\theta_{\mathrm{wp}}$, respectively.

Comparative study of these two methods allows to analyze the differences between a direct estimation procedure using a reduced number of data taking empirical values, respect to a second method based on an indirect estimation from a larger number of sampled values. Although at first it seems better to build models using $(\theta)$ measured on 
field, the fact is texture and OM data are much more frequent and available than soil water content data measured directly, so analysis of both alternatives can be interesting.

\subsubsection{Method 1: Direct estimation of $\theta$ values in the soil by modeling of environmental variables.}

This first method focuses on the evaluation of the empirical values of the soil water properties provided by the analytical determinations of the LUCDEME profiles. From the coordinates of the samples of the database 21 the values of environmental variables were obtained (Table 1). Due to the discrete nature of the qualitative variables, models proposed there is a coefficient for the effect of each class level, i.e. for each soil type or lithology (Pérez Cutillas et al., 2015).

Table 1. Description of the values from environmental variables and their descriptive statistics (range, mean, and standard deviation).

\begin{tabular}{lccc}
\hline Variable & Range & Mean & Standard deviation \\
\hline Altitude & $0-2057(\mathrm{~m})$ & 612 & \pm 407 \\
Slopes & $0-79\left({ }^{\circ}\right)$ & 7.5 & \pm 7.7 \\
Curvature (profile) & $-18-18$ & 0.008 & \pm 0.27 \\
Curvature (perpendicular) & $-20-22$ & 0.008 & \pm 0.41 \\
Flor accumulatin & $0-17($ pixel $) *$ & $1.6 *$ & \pm 1.8 \\
Precipitation & $250-771(\mathrm{~mm})$ & 390 & \pm 84 \\
Temperature & $8.2-18.4\left({ }^{\circ} \mathrm{C}\right)$ & 15.1 & \pm 2.07 \\
Direct radiation & $0.001-2.258 * *$ & $1.36 * *$ & \pm 0.12 \\
Diffuse radiation & $0.083-0.514 * *$ & $0.28 * *$ & \pm 0.01 \\
Duration os radiation & $40-4360(\mathrm{~h})$ & 4.03 & \pm 0.27 \\
NDVI - Winter & $-1-1$ & 0.05 & \pm 0.19 \\
NDVI - Summer & $-1-1$ & 0.03 & \pm 0.13 \\
CMI - Winter & $0-3.5$ & 1.21 & \pm 0.97 \\
FMI - Winter & $0-3$ & 0.83 & \pm 0.75 \\
IOI - Winter & $0-1.5$ & 0.31 & \pm 0.28 \\
CMI - Summer & $0-3.5$ & 1.21 & \pm 0.92 \\
FMI - Summer & $0-3$ & 0.95 & \pm 0.76 \\
IOI - Summer & $0-1.5$ & 0.39 & \pm 0.34 \\
Salne phase & & &
\end{tabular}

Saline phase

LUCDEME soils

Qualitative variables

MAGNA lithology

* Flow accumulation is rescaled to logarithmic values (Ln). ** Direct and diffuse radiation are scaled to $1 / 1000000$ from the original values. In the table they are expressed in MWh / $\mathrm{m}^{2}$. NDVI: Normalized vegetation index. CMI: Mineral composition index, Clay minerals; FMI: Mineral composition index, Ferrous minerals; IOI: Mineral composition index, iron oxide (Sabins, 1999). Landsat satellite images captured on 02/14/2009 (winter) and 07/24/2009 (summer). 
$\theta$ values available for each point were related in a table corresponding to the selected environmental variables with which regression models were built according to the method described below. A regression model in which the predictors are GIS layers can easily be represented by map algebra as it is a simple linear combination of these layers.

The pixel resolution for models was $400 \mathrm{~m}$, because it is a spatial resolution in some detail and be consistent with the modeling of these values at regional level. In addition, Pérez-Cutillas (2013) showed that using lower resolutions not substantially improves the predictive ability of the models. For the model of $\theta$ depending on environmental variables linear regression step forward (forward stepwise) using the Akaike information criterion (AIC) (1974) was applied.

\subsubsection{Method 2: Indirect estimation of $\theta$ values in the soil by means of pedotransfer functions.}

For the development of this method, a bibliographic review has been carried out that has allowed us to obtain a series of PTFs (Table 2), which exclusively use texture and $\mathrm{OM}$ values as input data. In some cases, the PTF calculation process required organic carbon (OC) values, so a transformation from $\mathrm{OM}$ to $\mathrm{OC}$ had to be carried out. Recent works have shown that the standard value of 1.724 proposed as a transfer factor by Van Bemmelen (Nelson and Sommers, 1982) is relatively low. These values are based on the hypothesis that soil $\mathrm{OM}$ contains $0.58 \%$ carbon $(\% \mathrm{OM}=\% \mathrm{OC} \times 1,724)$, but they have recommended values between 2 and 2.5 (Pribyl, 2010). The reality is that the proportion of OC in OM is highly variable for a range of soils and there is not an appropriate factor for all soils. In our case, once the calculations proposed by Pribyl (2010) had been carried out, excessively high values on $\mathrm{OM}$ were observed that do not match those provided by the empirical data. Consequently, we have chosen to maintain the Van Bemmelen factor, since it is better suited to our soils characterized by poor OC content (with mean values of $5 \%$ OM content).

Table 2. Relationships (by authors) of the pedotransfer functions (PTFs) with the field capacity $\left(\theta_{f c}\right)$ and wilting point $\left(\theta_{w p}\right)$ levels. Cl: Clay; Si: Silt; S: Sand; OC: Organic Carbon; OM: Organic Matter.

\begin{tabular}{|c|c|}
\hline Author & PTF \\
\hline $\begin{array}{l}\text { Pidgeon (1972) } \\
\text { (FAO) }\end{array}$ & $\begin{array}{l}\theta_{\mathrm{fc}}=[0.0361+(0.0016 * \mathrm{Si})+(0.003 * \mathrm{Cl})+(0.03 * \mathrm{OC})] / 0.95 \\
\theta_{\mathrm{wp}}=[-4.19+(0.19 * \mathrm{Si})+(0.39 * \mathrm{Cl})+(1.8 * \mathrm{OC})] / 100\end{array}$ \\
\hline $\begin{array}{l}\text { Lal (1979) } \\
\text { (USDA) }\end{array}$ & $\begin{array}{l}\theta_{\mathrm{fc}}=0.334-(0.003 * \mathrm{~S}) \\
\theta_{\mathrm{wp}}=0.247-(0.003 * \mathrm{~S})\end{array}$ \\
\hline $\begin{array}{l}\text { Rawls et al, (1982) } \\
\text { (USDA) }\end{array}$ & $\begin{array}{l}\theta_{\mathrm{fc}}=0.2576-(0.0020 * \mathrm{~S})+(0.0036 * \mathrm{Cl})+(0.0299 * \mathrm{OM}) \\
\theta_{\mathrm{wp}}=0.0260+(0.0050 * \mathrm{Cl})+(0.0158 * \mathrm{OM})\end{array}$ \\
\hline $\begin{array}{l}\text { Arruda et al. (1987) } \\
\text { (FAO) }\end{array}$ & $\begin{array}{l}\theta_{\mathrm{fc}}=[3.07439+(0.629329 *(\mathrm{Si}+\mathrm{Cl}))-(0.00343813 *(\mathrm{Si}+\mathrm{Cl}) 2)] / 100 \\
\theta_{\mathrm{wp}}=[398.889 *(\mathrm{Si}+\mathrm{Cl}) / 1308.09+(\mathrm{Si}+\mathrm{Cl})] / 100\end{array}$ \\
\hline $\begin{array}{l}\text { Dijkerman (1988) } \\
\text { (FAO) }\end{array}$ & $\begin{array}{l}\theta_{\mathrm{fc}}=[36.97-(0.35 * \mathrm{~S})] / 100 \\
\theta_{\mathrm{wp}}=[0.74+(0.39 * \mathrm{Cl})] / 10\end{array}$ \\
\hline
\end{tabular}




\begin{tabular}{|c|c|}
\hline Author & PTF \\
\hline $\begin{array}{l}\text { Hutson }(1992) \\
\text { (USDA) }\end{array}$ & $\begin{array}{l}\theta_{\mathrm{fc}}=\operatorname{Exp}(-3.43+(0.419 *(\mathrm{Cl}+\mathrm{Si}) 0.5)-1.83 *(0.001 *(\mathrm{Cl}+\mathrm{Si}) 1.5)) \\
\theta_{\mathrm{wp}}=\operatorname{Exp}(-4.384+(0.404 *(\mathrm{Cl}+\mathrm{Si}) 0.5)-9.85 *(0.0000001 *(\mathrm{Cl}+\mathrm{Si}) 3)\end{array}$ \\
\hline $\begin{array}{l}\text { Martinez (1996) } \\
\text { (USDA) }\end{array}$ & $\begin{array}{l}\theta_{\mathrm{fc}}=0.467-(0.071 * \ln S) \\
\theta_{\mathrm{wp}}=-0.234+(0.135 * \operatorname{lnCl})-(0.022 * \ln S)\end{array}$ \\
\hline $\begin{array}{l}\text { Batjes et al. (1996) } \\
\text { (FAO) }\end{array}$ & $\begin{array}{l}\theta_{\mathrm{fc}}=(0.3624 * \mathrm{Cl})+(0.11705 * \mathrm{~S})+(1.6054 * \mathrm{OM}) \\
\theta_{\mathrm{wp}}=(0.4600 * \mathrm{Cl})+(0.3045 * \mathrm{~S})+(2.0703 * \mathrm{OM})\end{array}$ \\
\hline $\begin{array}{l}\text { Masutti (1997) } \\
(\text { FAO) }\end{array}$ & $\begin{array}{l}\theta_{\mathrm{fc}}=-1.569+(0.429 *(\mathrm{Si}+\mathrm{Cl})) \\
\theta_{\mathrm{wp}}=-0.530+(0.0928 * \mathrm{Cl})+(0.301 * \mathrm{Si})\end{array}$ \\
\hline $\begin{array}{l}\text { Peraza (2003) } \\
\text { (FAO) }\end{array}$ & $\begin{array}{l}\theta_{\mathrm{fc}}=0.01188+(0.00002769 * \mathrm{Cl})+(0.00002335 * \mathrm{Si})+(0.00246 * \mathrm{OM}) \\
\theta_{\mathrm{wp}}=-0.01368+(0.000022619 * \mathrm{Cl})+(0.00001409 * \mathrm{Si})+(0.00123 * \mathrm{OM})\end{array}$ \\
\hline $\begin{array}{l}\text { Rawls (2004) } \\
\text { (USDA) }\end{array}$ & $\begin{array}{l}\theta_{\mathrm{fc}}=29.7528+(10.3544 *(0.0461615+0.290855 *(-0.837531+(0.430183 * \\
\mathrm{OC})-0.0496845 *(-0.837531+(0.430183 * \mathrm{OC}) 2+0.00704802 *(-0.837531 \\
+(0.430183 * \mathrm{OC}) 3+0.269101 *(-1.40744+(0.0661969 * \mathrm{Cl})-0.176528 * \\
((-0.837531+(0.430183 * \mathrm{OC}) *(-1.40744+(0.0661969 * \mathrm{Cl})))+0.0543138 \\
*((-0.837531+(0.430183 * \mathrm{OC})) 2 *(-1.40744+(0.0661969 * \mathrm{Cl})))+0.1982 \\
*((-1.40744+(0.0661969 * \mathrm{Cl})) 2)-0.060699 *((-1.40744+(0.0661969 * \\
\mathrm{Cl})) 3-0.320249 *(-1.51866+(0.0393284 * \mathrm{~S}))-0.0111693 *((-0.837531+ \\
(0.430183 * \mathrm{OC})) 2 *(-1.51866+(0.0393284 * \mathrm{~S})))+0.14104 *((-1.40744+ \\
(0.0661969 * \mathrm{Cl}) *(-1.51866+(0.0393284 * \mathrm{~S}))+0.0657345 *((-0.837531+ \\
(0.430183 * \mathrm{OC}) *(-1.40744+(0.0661969 * \mathrm{Cl})) *(-1.51866+(0.0393284 * \\
\mathrm{S})))-0.102026 *((-1.40744+(0.0661969 * \mathrm{Cl})) 2) *(-1.51866+(0.0393284 \\
* \mathrm{~S})))-0.04012 *((-1.51866+(0.0393284 * \mathrm{~S})) 2)+0.160838 *((-0.837531 \\
+(0.430183 * \mathrm{OC}) *((-1.51866+(0.0393284 * \mathrm{~S})) 2)-0.121392 *((-1.40744 \\
+(0.0661969 * \mathrm{Cl}) *((-1.51866+(0.0393284 * \mathrm{~S})) 2)-0.0616676 *(-1.51866 \\
+(0.0393284 * \mathrm{~S})) 3))))) \\
\theta_{\mathrm{wp}}=14.2568+7.36318 *(0.06865+0.108713 *(-0.837531+(0.430183 \\
* \mathrm{OC}))-0.0157225 *((-0.837531+(0.430183 * \mathrm{OC})) 2)+0.00102805 * \\
((-0.837531+(0.430183 * \mathrm{OC})) 3)+0.886569 *(-1.40744+(0.0661969 \\
* \mathrm{Cl}))-0.223581 *((-0.837531+(0.430183 * \mathrm{OC})) *(-1.40744+ \\
(0.0661969 * \mathrm{Cl})))+0.0126379 *((-0.837531+(0.430183 * \mathrm{OC})) 2) \\
*(-1.40744+(0.0661969 * \mathrm{Cl})))-0.017059 *(-1.40744+(0.0661969 \\
* \mathrm{Cl}) 2)+0.0135266 *((-0.837531+(0.430183 * \mathrm{OC})) *(-1.40744+ \\
(0.0661969 * \mathrm{Cl})) 2)-0.0334434 *(-1.40744+(0.0661969 * \mathrm{Cl}) 3)- \\
0.0535182 *(-1.51866+(0.0393284 * \mathrm{~S}))-0.0354271 *(-0.837531 \\
+(0.430183 * \mathrm{OC}) *-1.51866+(0.0393284 * \mathrm{~S}))-0.00261313 *((- \\
0.837531+(0.430183 * \mathrm{OC})) 2 *(-1.51866+(0.0393284 * \mathrm{~S})))- \\
0.154563 *(-1.40744+(0.0661969 * \mathrm{Cl})) *-(1.51866+(0.0393284 * \mathrm{~S})) \\
-0.0160219 *(-0.837531+(0.430183 * \mathrm{OC})) *(-1.40744+(0.0661969 \\
* \mathrm{Cl})) *(-1.51866+(0.0393284 * \mathrm{~S}))-0.0400606 *(-1.40744+ \\
(0.0661969 * \mathrm{Cl})) 2 *(-1.51866+(0.0393284 * \mathrm{~S}))-0.104875 *(-1.51866 \\
+(0.0393284 * \mathrm{~S}) 2)+0.0159857 *(-0.837531+(0.430183 * \mathrm{OC}) * \\
(-1.51866+(0.0393284 * \mathrm{~S}) 2)-0.0671656 *(-1.40744+(0.0661969 * \\
\mathrm{Cl}) *(-1.51866+(0.0393284 * \mathrm{~S}) 2)\end{array}$ \\
\hline
\end{tabular}

In conclusion, the operations used in this method are based on the calculation of PTFs, and on obtaining the values of the soil water content under thresholds of $\left(\theta_{\mathrm{fc}}\right)$ and $\left(\theta_{\mathrm{wp}}\right)$, based on the values of the granulometric composition of the textures (Pérez Cutillas 
et al.,2013) and on the OM (Pérez Cutillas et al., 2017). To determine which PTFs are best suited to the study area, and in order to select a group of assumable functions according to the objectives of this work, better PTFs were selected by a statistical correlation (higher $\mathrm{R}^{2}$ ) with the texture and $\mathrm{OM}$ values derived from the analytical determinations in the profile samples collected in the LUCDEME project.

\subsubsection{Comparative analysis of the two methods}

This part of the methodology focuses on possible sources of the discordances discovered on soil water content layers. By means of map algebra, the differences between the results derived from the two methods have been calculated, representing them in a georeferenced form in each point of the territory. To interpret these results, the figures close to zero indicate that the two estimation methods present high similarities in their results, while an increase, in a positive or negative sense, in the resulting values expresses an increase in their differences. By convention we will adopt as a standard difference between the 'environmental variables Model' and the 'PTF Model' that in which, for negative values, the PTF method provides higher water content estimates at a given $\theta$, while for positive values it is the method based on the direct modeling of the analytical data of the LUCDEME project that offers the greater estimate.

The relationship of these differences will be established by statistical correlation techniques. A low correlation coefficient will show a poor association of the variable in question with the differences in results between the methods, with the opposite being true when high correlation coefficients are obtained. In this way, the correlation will allow us to detect in a simple and efficient way which variables are affecting the discrepancies in the results and thus provide a starting criterion for the improvement in the elaboration of future estimates of these soil properties. The statistical analysis includes the 69,394 values corresponding to the digital levels of the pixels (DLP) of the 'difference' layers.

\subsubsection{Evaluation of texture values and $M O$ in the estimation of $\theta$}

For this, the Pearson correlation index has been adopted, since it measures the linear relationship between two quantitative random variables and, unlike covariance, the Pearson method is independent of the scale of measurement of the variables,

$$
\rho_{X, Y}=\frac{\sigma_{X Y}}{\sigma_{X} \sigma_{Y}}
$$

where,

$\sigma_{X Y}$ is the covariance of $(\mathrm{X}, \mathrm{Y})$

$\sigma_{X} \sigma_{Y}$ are the standard deviations of (X and $\left.\mathrm{Y}\right)$

which, applied to the total of the samples, is expressed as follows:

$$
r_{x y}=\frac{\sum_{n} x_{i} y_{i}-\sum x_{i} \sum y_{i}}{\sqrt{\sum_{n} x_{i}^{2}-\left(\sum x_{i}\right)^{2}} \sqrt{\sum_{n} y_{i}^{2}-\left(\sum y_{i}\right)^{2}}}
$$


The Spearman correlation coefficient has also been applied, which, like the Pearson correlation coefficient, oscillates between -1 and +1 , representing negative or positive associations, respectively. When it adopts a value of 0 it indicates that there is no correlation but neither independence of the variables. Unlike Pearson's, the Spearman correlation coefficient is able to detect monotonous associations that are not strictly linear.

$$
\rho=1-\frac{6 \sum D^{2}}{N\left(N^{2}-1\right)}
$$

A low value of the Pearson correlation and a high value of the Spearman correlation may be due to a non-linear pattern of the point cloud.

As a general rule, the correlation coefficients measure the intensity of the existing association between variables. The levels of statistical significance in the correlations depend on the number of samples; with a high number, statistically significant values will almost always be obtained. In our case, and by way of example, starting from almost 70,000 DLP with a correlation coefficient as low as 0.0075 , significant values can be obtained at the level of $p<0.05$. Therefore, in these cases the statistical significance may lack relevance, so it has been necessary to adopt another method to choose the variables that are worth paying attention to with regard to the differences between the two methods.

To select these variables, we have arbitrarily considered the values of the Pearson coefficients (or, if necessary, Spearman), with absolute value $>0.30$, which will indicate an explained variance of approximately $10 \%$ for the variable under study. These indices show the degree of association between the difference between the methods and a particular variable, with the highest values suggesting that the difference may be due to the effect of that variable somewhere in the process. This information allows us to check the coefficients of each of the variables obtained in the modeling processes of the texture fractions, $\mathrm{OM}$ and $\theta$, and thereby to know the intensity of their effect on the final results.

A second stage is based on statistical analysis of the relationships of these method differences with the models of texture fractions and OM, since these values are the input variables for the estimation of $\theta$ by PTFs. For this, a complex data cloud must be characterized through a graph showing the effect of the variables (texture and MO), but the use of a linear regression model can cause a notable loss of information, as well as covering up the problem we are analyzing and distorting the conclusions. An alternative to the use of these regression models is the use of Generalized Additive Models (GAM), which incorporate nonparametric functions together with those that adapt better to nonlinear data structures.

$$
g(E(Y))=\beta_{0}+f_{1}\left(x_{1}\right)+f_{2}\left(x_{2}\right)+\cdots+f_{m}\left(x_{m}\right)
$$

where,

$\beta_{0}$, is the intersection or term "constant".

$f_{1}\left(x_{1}\right)$, functions of the variable 
The graphic representation of our data will help the analysis of the results, since the values of the correlation coefficients tell us the information corresponding to the variability that is explained by a variable, but do not show the evolution of the dispersion of the data of the variables. The following example in Figure 2, will advise to indicate better the differences between the two methods of estimation of soil moisture content derived from the soil water potential, related to $\left(\theta_{\mathrm{fc}}\right)$ and $\left(\theta_{\mathrm{wp}}\right)$. The cloud dispersion of DLP is divided into two parts, separated by the value 0 . Points represented in positive values (top), show higher estimates for water content in the indirect method (PTFs), while the points representing negative values (bottom) describe higher estimates for water content in the environmental variables modelling method. To represent the effect of the described variable, a line associated to points accumulation is drawn.

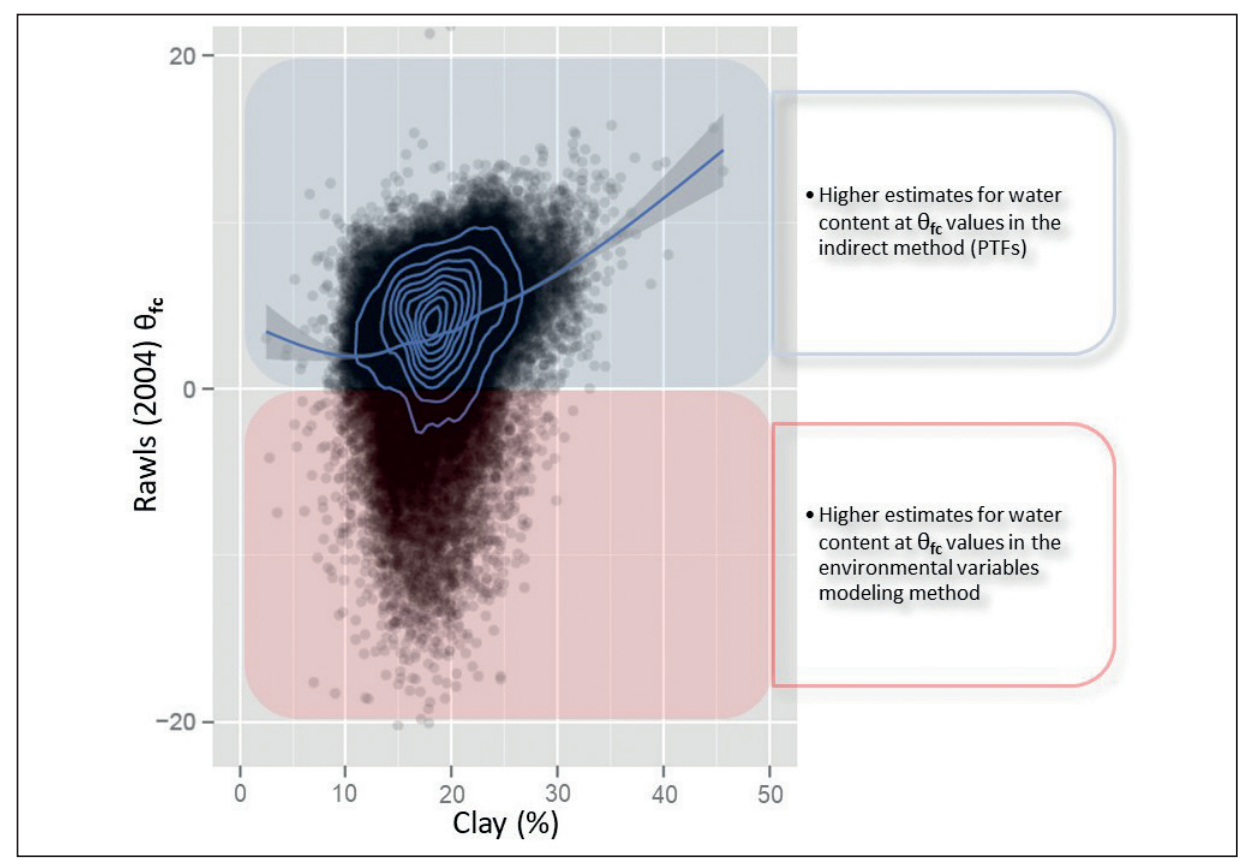

Figure 2. Representation as an example of dispersion of the point cloud relating two variables (Differences vs texture or OM) adjusted by a Generalized Additive Model (GAM). The values located in the blue frame show higher estimation values for the method elaborated from PTFs. The values represented in the red frame show higher estimation values for the method developed by modeling the $\theta$ values.

\section{Results and discussion}

\subsection{Indirect estimation of soil moisture values at $\theta_{f c}$ and $\theta_{w p}$}

To determine which PTFs are best suited to the study area, the coefficients of determination of the values obtained from the PTFs and the $\theta$ values available in the field samplings of the LUCDEME project have been calculated using a linear regression (Table 3). 
Table 3. Values of the Pearson correlation coefficient $(R)$, coefficient of determination $\left(R^{2}\right)$, and the standard error between the results obtained in the application of PTFs and the $\theta$ values available in the field samplings, for values at $\theta_{f c}$ and $\theta_{w p}$.

\begin{tabular}{|l|c|c|c|c|c|c|}
\hline \multirow{2}{*}{\multicolumn{1}{c|}{ PFT }} & \multicolumn{3}{|c|}{$\theta_{\text {fc }}$} & \multicolumn{3}{c|}{$\theta_{\text {wp }}$} \\
\cline { 2 - 7 } & $\mathbf{R}$ & $\mathbf{R}^{2}$ & Standard Error & $\mathbf{R}$ & $\mathbf{R}^{2}$ & Standard Error \\
\hline Pidgeon (1972) & 0.663 & 0.440 & 5.91232 & 0.717 & 0.514 & 4.24083 \\
\hline Lal (1979) & 0.577 & 0.333 & 6.45414 & 0.559 & 0.312 & 5.04635 \\
\hline Rawls (1982) & 0.660 & 0.435 & 5.93746 & 0.687 & 0.472 & 4.42086 \\
\hline Arruda (1987) & 0.608 & 0.370 & 6.27260 & 0.561 & 0.315 & 5.03844 \\
\hline Dijkerman (1988) & 0.577 & 0.333 & 6.45414 & 0.495 & 0.245 & 5.28734 \\
\hline Hutson (1992) & 0.562 & 0.316 & 6.53424 & 0.526 & 0.277 & 5.17534 \\
\hline Martinez (1996) & 0.502 & 0.252 & 6.79855 & 0.510 & 0.261 & 5.14543 \\
\hline Batjes (1996) & 0.207 & 0.043 & 7.73089 & 0.585 & 0.343 & 4.93426 \\
\hline Masutti (1997) & 0.577 & 0.333 & 6.45414 & 0.508 & 0.258 & 5.24199 \\
\hline Peraza (2003) & 0.450 & 0.203 & 7.05558 & 0.549 & 0.301 & 5.08838 \\
\hline Rawls (2004) & 0.686 & 0.470 & 5.75156 & 0.594 & 0.353 & 4.89387 \\
\hline
\end{tabular}

With the calculated values at $\theta_{\text {fc }}$ and $\theta_{\text {wp }}$, the five PTFs that best fit the sampled data were selected; these are the functions proposed by Pidgeon (1972), Lal (1979), Rawls et al. (1982), Arruda et al. (1987) and Rawls et al. (2004).

The values obtained in the estimation on both soil moisture show a high disparity, and also show quite different spatial patterns for the two $\theta$. This contrasts significantly, if we observe the high coefficients - shown by the correlation tables - between the PTFs themselves (Tables 4 and 5), values that have been validated with the data of the layers estimated by the PTFs with the $\theta$ values sampled in the field, using a bivariate correlation.

Focusing on the correlations between the $\theta$ with respect to the PTFs, Rawls (1982) gave the best coefficients at $\theta_{\text {fc }}$ and $\theta_{\text {wp }}(0.298$ and 0.345 , respectively), while Lal (1979) and Arruda (1987) showed lower indices for our study area. However, despite this, a pattern is observed that is repeated in all cases, where the best fit is obtained with the values related to the wilting point rather than those corresponding to the field capacity.

Table 4. Bivariate correlation table of the $\theta_{f_{c}}$ values of the LUCDEME analyses and the $\theta_{f_{c}}$ values obtained in the PTFs estimates.

\begin{tabular}{|c|c|c|c|c|c|c|}
\hline \multicolumn{7}{|c|}{ Correlations } \\
\hline & $\theta_{\mathrm{fc}}$ & Rawls 82 & Rawls 04 & Pidgeon & Lal & Arruda \\
\hline$\theta_{\mathrm{fc}}$ & 1 & $.298 * *$ & $.236 * *$ & $.301 * *$ & $.166^{* *}$ & $.156 * *$ \\
\hline Rawls 82 & $.298 * *$ & 1 & $.813 * *$ & $.986 * *$ & $.549 * *$ & $.498 * *$ \\
\hline Rawls 04 & $.236 * *$ & $.813 * *$ & 1 & $.794 * *$ & $.869 * *$ & $.835 * *$ \\
\hline Pidgeon & $.301 * *$ & $.986 * *$ & $.794 * *$ & 1 & $.508 * *$ & $.520 * *$ \\
\hline Lal & $.166^{* *}$ & $.549 * *$ & $.869 * *$ & $.508 * *$ & 1 & $.915 * *$ \\
\hline Arruda & $.156^{* *}$ & $.498 * *$ & $.835 * *$ & $.520 * *$ & $.915 * *$ & 1 \\
\hline
\end{tabular}

Pearson's correlation coefficient. ** The correlation is significant at the 0.01 level (bilateral) 
Table 5. Bivariate correlation table of the $\theta_{w p}$ values of the LUCDEME analyses and the $\theta_{w p}$ values obtained in the PTFs estimates.

\begin{tabular}{|l|c|c|c|c|c|c|}
\hline \multicolumn{7}{|c|}{ Correlations } \\
\hline & $\theta_{\mathrm{wp}}$ & Rawls 82 & Rawls 04 & Pidgeon & Lal & Arruda \\
\hline$\theta_{\mathrm{wp}}$ & 1 & $.345^{* *}$ & $.260^{* *}$ & $.313^{* *}$ & $.234^{* *}$ & $.168^{* *}$ \\
\hline Rawls 82 & $.345^{* *}$ & 1 & $.724^{* *}$ & $.923^{* *}$ & $.514^{* *}$ & $.525^{* *}$ \\
\hline Rawls 04 & $.260^{* *}$ & $.724^{* *}$ & 1 & $.873^{* *}$ & $.885^{* *}$ & $.904^{* *}$ \\
\hline Pidgeon & $.313^{* *}$ & $.923^{* *}$ & $.873^{* *}$ & 1 & $.748^{* *}$ & $.801^{* *}$ \\
\hline Lal & $.234^{* *}$ & $.514^{* *}$ & $.885^{* *}$ & $.748^{* *}$ & 1 & $.911^{* *}$ \\
\hline Arruda & $.168^{* *}$ & $.525^{* *}$ & $-.904^{* *}$ & $.801^{* *}$ & $.911^{* *}$ & 1 \\
\hline
\end{tabular}

Pearson's correlation coefficient. ** The correlation is significant at the 0.01 level (bilateral)

\subsection{Comparison of the estimation methods for soil moisture values at $\theta_{f c}$ and $\theta_{w p}$}

The results presented in this section focus on the comparative analysis of the $\theta$ estimates already described. Figures 3 and 4 show the layers resulting from the arithmetic operation 'difference' between the $\theta$ values estimated by PTFs and the $\theta$ values estimated by modeling, and to which the term 'Differences' of $\theta$ will be assigned in the following.

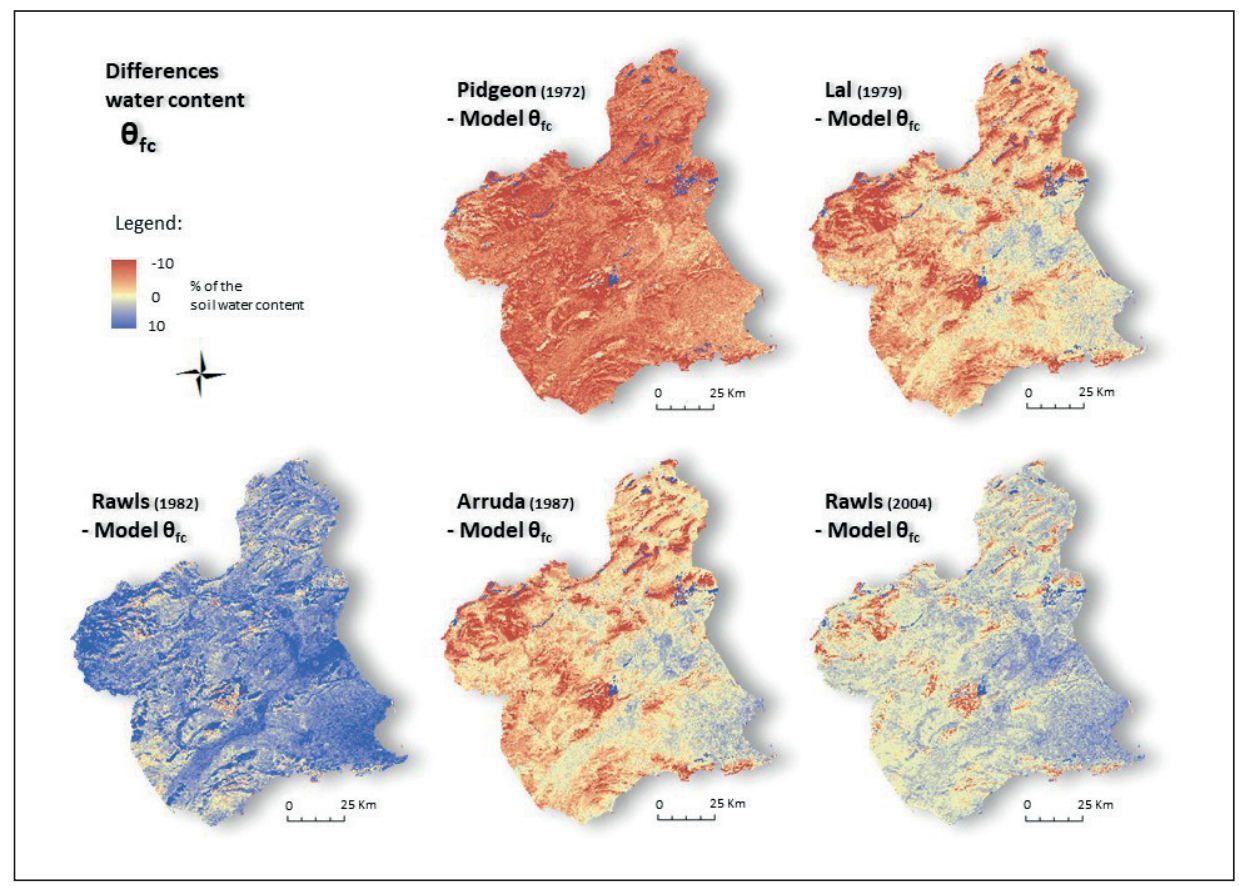

Figure 3. Raster layers of the method Differences in the estimation of the soil water content $(\theta f c)$. The values of all the layers are adjusted to the range 10 to $-10 \%$ of the water content in the soil; the positive values are shown in blue, indicating a higher soil water content in the indirect method (PTFS), and the negative ones are shown in red, indicating a higher $\theta$ for the direct method (model). 


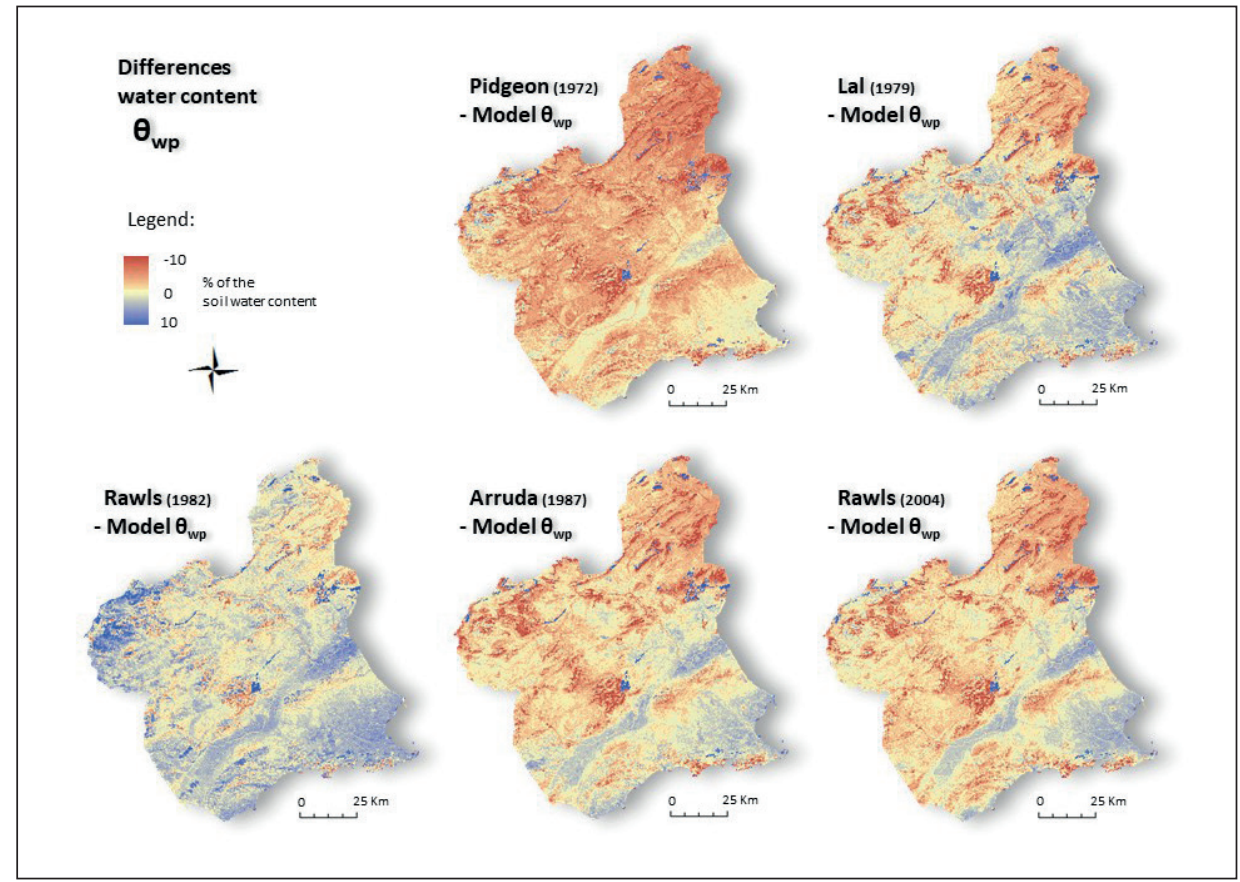

Figure 4. Raster layers of the method Differences in the estimation of the soil water content $(\theta w p)$. The values of all the layers are adjusted to the range 10 to $-10 \%$ of the water content in the soil; the positive values are shown in blue, indicating a higher soil water content in the indirect method (PTFs), and the negative ones are shown in red, indicating a higher $\theta$ for the direct method (model).

Being developed in the relationship between the textures and $\mathrm{OM}$ in the divergences found between the two methods. As a reference for the rest of the statistical analyses that are presented later, Table 6 shows the average values $(\bar{x})$ and standard deviation $(\sigma)$ for the total of DLP obtained in the different layers Differences in the $\theta$.

Tabla 6. Average values $(\bar{x})$ and standard deviation $(\sigma)$ for the data of the Differences between the methods, for the parameters at $\theta_{f c}$ and $\theta_{w p}$.

\begin{tabular}{|c|c|c|c|c|c|}
\hline & Pidgeon $\theta_{\mathrm{fc}}$ & Lal $\theta_{\mathrm{fc}}$ & Rawls82 $\theta_{\mathrm{fc}}$ & Arruda $\theta_{\mathrm{fc}}$ & Rawls04 $\theta_{\mathrm{fc}}$ \\
\hline$\overline{\boldsymbol{x}}$ & -7.31 & -2.98 & 7.01 & -2.16 & 3.67 \\
\hline $\boldsymbol{\sigma}$ & \pm 4.81 & \pm 5.51 & \pm 5.58 & \pm 5.46 & \pm 4.98 \\
\hline
\end{tabular}

\begin{tabular}{|c|c|c|c|c|c|}
\hline & Pidgeon $\theta_{\mathrm{wp}}$ & Lal $\theta_{\mathrm{wp}}$ & Rawls82 $\theta_{\mathrm{wp}}$ & Arruda $\theta_{\mathrm{wp}}$ & Rawls04 $\theta_{\mathrm{wp}}$ \\
\hline$\overline{\boldsymbol{x}}$ & -3.78 & -0.17 & 1.93 & -1.50 & -1.63 \\
\hline $\boldsymbol{\sigma}$ & \pm 3.56 & \pm 4.14 & \pm 3.55 & \pm 3.94 & \pm 3.90 \\
\hline
\end{tabular}




\subsection{Cumulative spatial distribution of the Difference values}

As an initial analysis of the data obtained by the differences between the two methods under study, we can extract a summary valuation of the percentages of the accumulated number of pixels, or what is the same, the representation of the percentages of surface estimated by the PTFs in relation to the origin of the $\theta$ values used. For this we use the figures in which the number of accumulated pixels is represented with respect to the values of the differences between the estimate obtained by the PTFs calculation and the direct estimation method for $\theta_{\text {fc }}$ (Fig. 5) and $\theta_{\text {wp }}$ (Fig. 6), in the five cases that have been analyzed. The values shown in the positive ranges correspond to the percentages of the surface area that show a higher $\theta$ for the estimation by the indirect method, obtained through the use of the PTFs. The values located in the negative part of the graph show the surface area corresponding to values estimated by the direct method and with a moisture content higher than $\theta_{\mathrm{fc}}$ value.

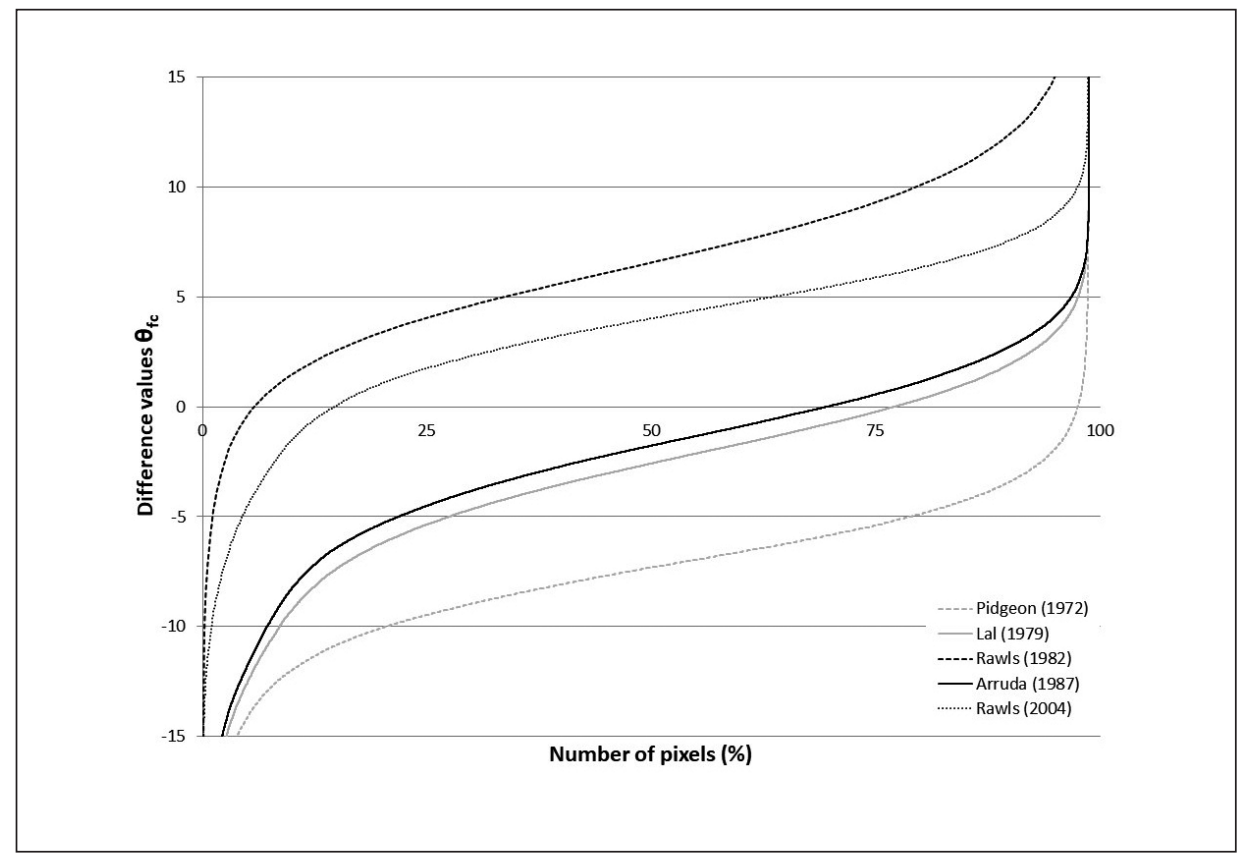

Figure 5. Cumulative spatial distribution of the Difference values for the five cases under study at $\theta f c$. The values shown in the positive ranges correspond to the percentage of surface area that show a higher soil water content for the estimation by the indirect method. Values located in the negative values part show the surface area (\%) with the highest moisture content estimated by the direct method.

For the moisture content of the soil subjected to $\theta_{\mathrm{fc}}$, a large dispersion is observed between the values represented by the five PTF algorithms analyzed. With surface areas as different as the differences between the $\theta$ methods obtained by Rawls $82 \theta_{f c}$ and 
Pidgeon $\theta_{f c}$, in which the former represents almost the entire surface area with a higher moisture estimate at $\theta_{\mathrm{fc}}$ for the indirect method, while Pidgeon $\theta_{f c}$ shows the greater part of its surface area with soil moisture values that are higher than with the direct method. In the same trend, but with smaller surface percentages, are the RawlsO4 $\theta_{f c}$ and Lal $\theta_{f c}$. Finally, Arruda $\theta_{f c}$ shows a more centered position but with values close to those shown by Lal $\theta_{f c}$, with about $70 \%$ of its surface area having a higher $\theta$ value when estimated with the direct method.

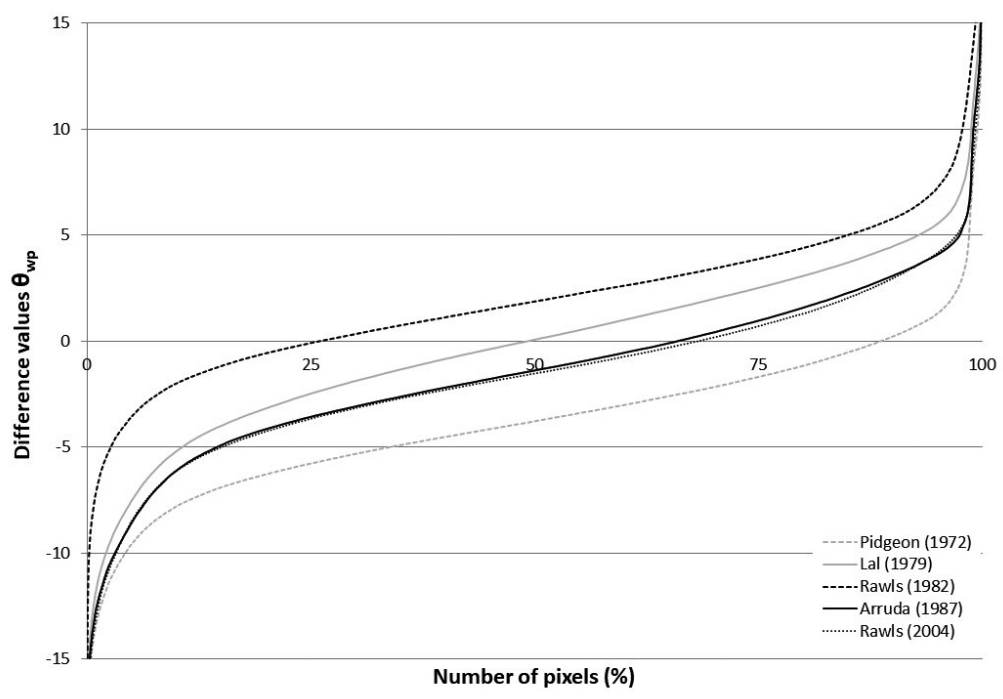

Figure 6. Cumulative spatial distribution of the Difference values for the five cases under study at $\theta w p$. The values shown in the positive ranges correspond to the percentage of surface area showing a higher soil water content for the estimation by the indirect method. Values in the negative ranges show the surface area (\%) for which the highest moisture content was estimated by the direct method.

Regarding the moisture content at $\theta_{\mathrm{wp}}$, a greater uniformity of the results is observed among the cases under study. But, as for $\theta_{\mathrm{fc}}$, the values of the differences in the five cases keep the same position.

\subsection{Statistical association of textures and $\mathrm{OM}$ with the differences}

In order to elaborate this analysis, the relationship between the four variables (clay, silt, sand and OM) was measured using the Pearson and Spearman correlation indexes, allowing us to describe the behavior of these differences with respect to textures and $\mathrm{OM}$ as independent variables, which shows the association between them (Table 7). 
Table 7. Data correlation analysis (DLP) of the method Differences for $\theta$ with respect to the DLP of textures and organic matter (OM). The values are expressed by the Pearson coefficient and the quadrant of the coordinate axis in which the point cloud of the data analyzed is located. The degree of association is determined with values of coefficients greater than $+/-0.30$.

\begin{tabular}{|l|c|c|c|c|c|c|c|c|}
\hline & \multicolumn{2}{|c}{ Clay } & \multicolumn{2}{c|}{ Sand } & \multicolumn{2}{c|}{ Silt } & \multicolumn{2}{c|}{ OM } \\
\cline { 2 - 8 } & Pearson & Spearman & Pearson & Spearman & Pearson & Spearman & Pearson & Spearman \\
\hline Rawls82 $\theta_{\text {fc }}$ & 0.287 & $\mathbf{0 . 3 9 2}$ & $\mathbf{- 0 . 3 5 0}$ & $\mathbf{- 0 . 4 1 1}$ & $\mathbf{0 . 3 0 2}$ & $\mathbf{0 . 3 4 3}$ & $\mathbf{0 . 4 0 1}$ & $\mathbf{0 . 3 6 3}$ \\
\hline Rawls04 $\theta_{\text {fc }}$ & 0.170 & 0.238 & -0.230 & $\mathbf{- 0 . 3 2 1}$ & 0.209 & 0.289 & -0.260 & -0.259 \\
\hline Arruda $\theta_{\text {fc }}$ & 0.223 & $\mathbf{0 . 3 5 1}$ & $\mathbf{- 0 . 3 6 1}$ & $\mathbf{- 0 . 5 0 5}$ & $\mathbf{0 . 3 9 4}$ & $\mathbf{0 . 5 3 0}$ & $\mathbf{- 0 . 3 9 7}$ & $\mathbf{- 0 . 4 7 1}$ \\
\hline Lal $\theta_{\text {fc }}$ & 0.215 & $\mathbf{0 . 3 2 2}$ & $\mathbf{- 0 . 3 8 8}$ & $\mathbf{- 0 . 5 3 7}$ & $\mathbf{0 . 3 9 4}$ & $\mathbf{0 . 5 2 7}$ & $\mathbf{- 0 . 3 8 4}$ & $\mathbf{- 0 . 4 5 7}$ \\
\hline Pidgeon $\theta_{\text {fc }}$ & 0.161 & 0.223 & -0.226 & -0.284 & 0.226 & 0.293 & 0.121 & 0.123 \\
\hline Rawls82 $\theta_{\text {wp }}$ & 0.260 & 0.261 & -0.163 & -0.165 & 0.068 & 0.085 & 0.261 & 0.226 \\
\hline Rawls04 $\theta_{\text {wp }}$ & $\mathbf{0 . 4 7 8}$ & $\mathbf{0 . 4 9 9}$ & $\mathbf{- 0 . 4 4 8}$ & $\mathbf{- 0 . 5 1 1}$ & $\mathbf{0 . 3 2 3}$ & $\mathbf{0 . 4 0 1}$ & -0.252 & -0.277 \\
\hline Arruda $\theta_{\text {wp }}$ & 0.283 & 0.233 & $\mathbf{- 0 . 4 1 9}$ & $\mathbf{- 0 . 4 2 5}$ & $\mathbf{0 . 4 3 6}$ & $\mathbf{0 . 5 1 0}$ & $\mathbf{- 0 . 3 5 1}$ & $\mathbf{- 0 . 3 8 6}$ \\
\hline Lal $\theta_{\text {wp }}$ & 0.273 & 0.280 & $\mathbf{- 0 . 4 8 2}$ & $\mathbf{- 0 . 5 4 9}$ & $\mathbf{0 . 4 8 6}$ & $\mathbf{0 . 5 7 1}$ & $\mathbf{- 0 . 3 3 2}$ & $\mathbf{- 0 . 3 7 5}$ \\
\hline Pidgeon $\theta_{\text {wp }}$ & $\mathbf{0 . 3 3 4}$ & 0.283 & $\mathbf{- 0 . 4 0 7}$ & $\mathbf{- 0 . 4 0 2}$ & $\mathbf{0 . 3 7 0}$ & $\mathbf{0 . 4 3 7}$ & 0.031 & -0.012 \\
\hline
\end{tabular}

Regarding this level of exploration, we can observe that for the textures a pattern is repeated in all the Difference layers, where the variables clay and silts represent positive values of coefficients and sands represent negative values. The trend of this pattern does not seem to be due to the intrinsic structure of each of the PTFs, but rather to the fractions of input texture to the model, which exert a similar effect in all calculations. This is very interesting, since the structural variations in the texture models play an important role in the estimation of these hydraulic properties. In contrast, the OM shows a more variable result, most likely conditioned by the PTFs, due a different relationship is observed with Rawls82 and Pidgeon (coefficients +), than with the rest of the Differences (coefficients -), aspect not observed in the effects of textures (Table 7). The functions presented by Rawls 82 and Pidgeon show high correlation values ( 0.986 for $\theta_{\mathrm{fc}}$ and 0.923 for $\theta_{\mathrm{wp}}$ in Tables 4 and 5), indicating a high similarity between the PTFs. This agrees with the coefficients of determination $\left(\mathrm{R}^{2}\right)$ obtained in the bivariate correlations between the results of the PTFs and the original values of $\theta$ (LUCDEME), in which they give the highest values for the explanation of the variance in the $\theta\left(0.298\right.$ and 0.301 for $\theta_{\mathrm{fc}}$ and 0.345 and 0.313 for $\theta_{\text {wp }}$, respectively, in Table 3). 
In general, the correlation coefficients indicate that the sands and silts have the greatest associations in the differences. Considering the GAM models elaborated, it is possible to point out the existence of similar patterns for each of the variables with respect to the values of the differences, a logical pattern because the values of the coordinate axis are related to the same variable.

For the clays, a similar trend is observed in all the cases studied, where the increase in the percentage of this textural fraction results in a modification of the values of the Differences; that is to say, as the percentage of clays increases, the difference in the values of field capacity in the soil with the values obtained by the PTFs decreases and, reaching a value of ' 0 ', the values calculated by the direct method begin to be greater. Examining the values by the estimation of the soil water content at two fixed matric potential values, it can be seen that at $\theta_{\mathrm{fc}}$, the representation of the data in both Rawls82 $\theta_{f c}$ (Fig. 7) and Rawls04 $\theta_{f c}$ shows that the values of $\theta$ for this content are higher for the estimation by the direct method than those obtained with the PTFs, for most of the percentages of texture of the clays. On the other hand, Lal $\theta_{f_{c}}$ and Pidgeon $\theta_{f c}$ present the inverse result, the PTFs method giving the highest moisture content at $\theta_{f c}$. Arruda $\theta_{f c}$ presents a more complex evolution: places with less than $25 \%$ of clay had lower moisture contents when using the results of the PTFs, while for clay values higher than $25 \%$ the direct $\theta$ method gave the lowest values. Regarding the values of $\theta_{\text {wp }}$, Rawls82 $\theta_{w p}$, Arruda $\theta_{w p}$ and Pidgeon $\theta_{w p}$ gave results similar to those of $\theta_{\text {fc }}$, while Rawls04 $\theta_{w p}$ and Lal $\theta_{w p}$ showed modified results. Higher moisture content values were found in the PTFs results for much of the data for the RawlsO4 $\theta_{w p}$, while the opposite occurred for the values of Lal $\theta_{w p}$.

For sands the case is reversed with respect to clays, and the general trend shows that as the percentage of sand increases, the curve representing the values of the differences decreases. Examining the results of the $F C$ values, the values of the differences show a similar pattern to the clays, with Rawls82 $\theta_{f_{c}}$ and Rawls04 $\theta_{f_{c}}$ presenting higher $\theta$ values with the direct method, Lal $\theta_{f c}$ and Pidgeon $\theta_{f c}$ giving higher $\theta$ values with the indirect method, and Arruda $\theta_{f c}$ showing a transition in the values of both methods. The same happens with the data at the $\theta_{\text {wp }}$ level, where Rawls82 $\theta_{w p}$, Arruda $\theta_{w p}$ and Pidgeon $\theta_{w p}$ again present similar values with respect to the differences at $\theta_{f c}$, while Rawls04 $\theta_{w p}^{w p}$ and Lal $\theta_{w p}$ show modified values.

Finally, the texture fraction of the silts presents an upward trend similar to that shown by the clays. The results for the $\theta_{\mathrm{fc}}$ values show again that Rawls $82 \theta_{f c}$ and Rawls $04 \theta_{f c}$ have the majority of their data as positive values, which indicates $\theta$ values estimated with the direct method lower than those obtained with the method that uses the PTFs. Only Pidgeon $\theta_{f c}$ has most of its values below 0 , indicating a higher moisture index in the results of the direct method. For their part, Arruda $\theta_{f c}$ and $\operatorname{Lal} \theta_{f c}$ (Fig. 7) have points with both positive and negative values, which suggests a more diverse behavior. In both cases, there are lower $\theta$ values arrived at with the indirect method; but for silts contents higher than $25 \%$ and $50 \%$, respectively, the result is inverted. If we observe the values for $\theta_{\text {wp }}$, the previous trend is repeated in all cases, except for Rawls04 $\theta_{w p}$. This shows that the influence of silts on the values of the differences, despite having high coefficients, remains quite stable for both $\theta$. 


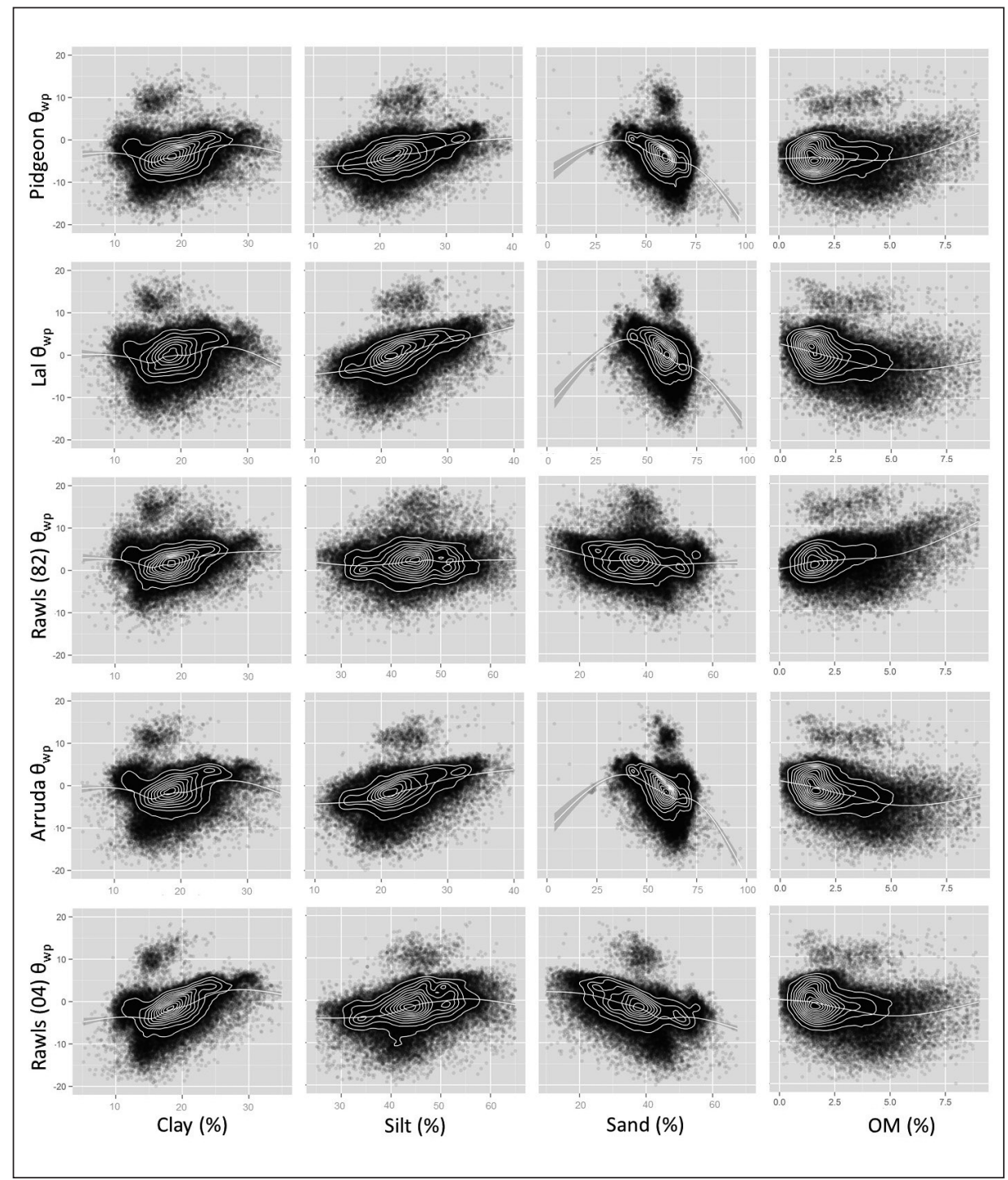

Figure 7. Representation of the dispersion of the points clouds between the variables clay, silt, sand, Organic Matter (OM) and the Differences in PTFs adjusted by means of a Generalized

Additive Model (GAM). The positive data show higher estimation values for the method developed from PTFs. Negative data show higher estimation values for the method developed by modeling $\theta$ values.

The OM appears as the most diverse variable of those discussed in this section, since the correlation coefficients show an alternation of the gradients represented, adopting an upward trend for Rawls82 and Pidgeon and a downward one for the rest. The values of 
$\theta_{\text {fc }}$ show results similar to those for the clays and sands. All cases maintain these values for $\theta_{\mathrm{wp}}$, except for Rawls04 $\theta_{w p}$ (Fig. 8) that inverts its results to show soil moisture values higher than those obtained by the method involving modeling of environmental variables.

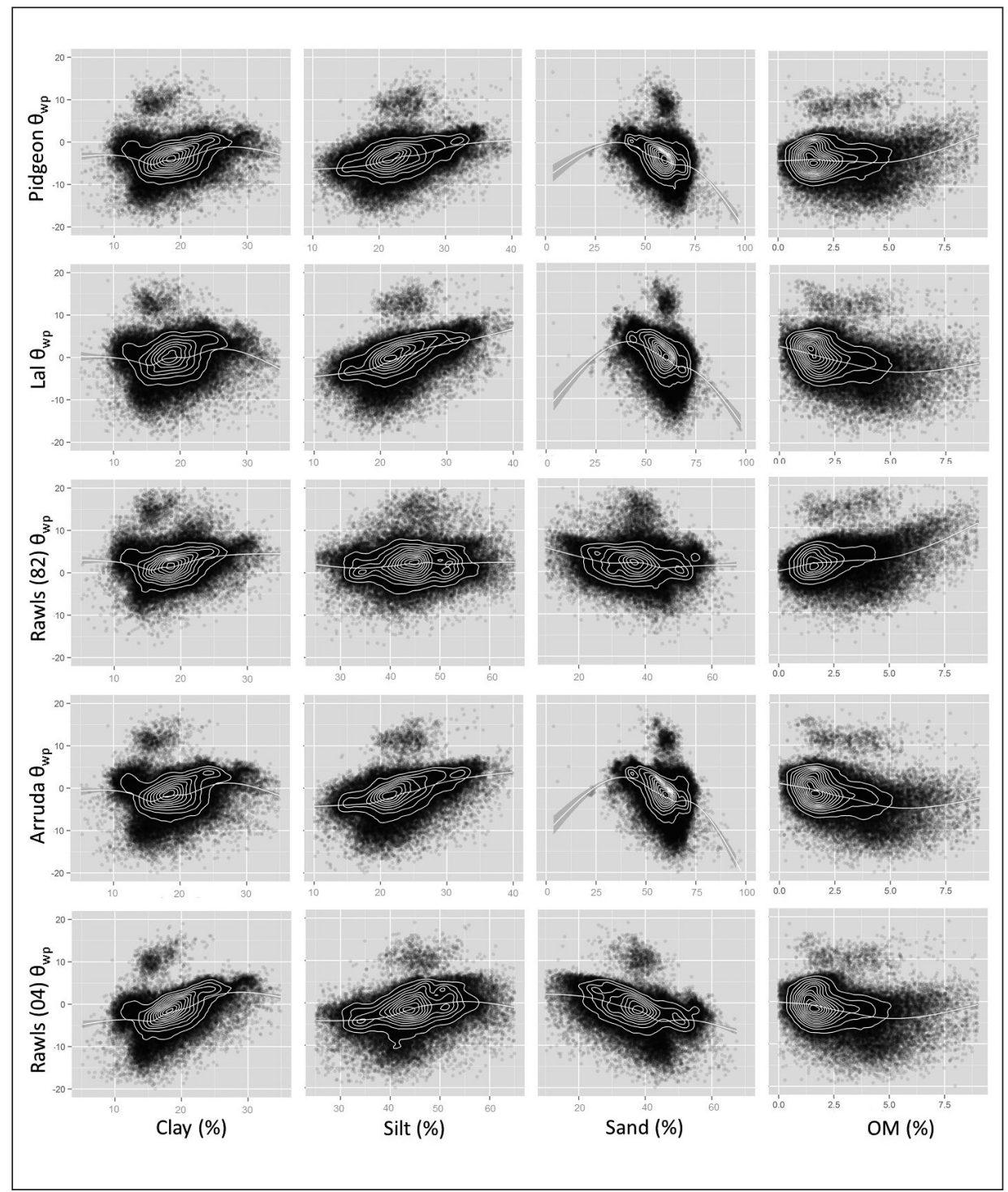

Figure 8. Representation of the dispersion of the point cloud between the variables clay, silt, sand, Organic Matter (OM) and the Differences in PTFs adjusted by means of a Generalized Additive Model (GAM). The positive data show higher estimation values for the method developed from PTFs. Negative data show higher estimation values for the method developed by modeling $\theta$ values. 


\section{Conclusions}

The exploration of several procedures for estimating the water content of the soil at a regional scale through the analysis of the soil water content allows us to discuss the effect of the variables used in its prediction. This diagnosis has shown a strong influence of textures and $\mathrm{OM}$ in the study of the differences between the two methods, which is interesting for the conclusions that can be drawn from their spatial distribution and variability. The analyses of the spatially cumulative distribution in the comparison of the two methods broadly show a greater dispersion of the data associated at $\theta_{\mathrm{fc}}$, which indicates that these values, associated with the field capacity situation, are more difficult to estimate than the wilting point values $\left(\theta_{\mathrm{wp}}\right)$. On the other hand, the similar relationship regarding the positions occupied by the five cases analyzed for the two $\theta$ values suggests that, despite finding certain differences between the methods analyzed, there is a considerable degree of consistency between them.

The comparison of the Differences shows that the texture fractions included in the model exert a similar effect in all calculations. This shows that the structural variations in the models of the texture fractions play an important role in the estimation of these hydraulic properties. In contrast, the OM shows a more variable result, which could be conditioned by the intrinsic structure of each PTF.

\section{References}

Akaike, H. 1974. A new look at the statistical model identification. IEEE Transactions on Automatic Control 19, 716-723. https://doi.org/10.1109/TAC.1974.1100705.

Arruda, F.B., Zullo Jr, J., Oliveira, J.B. 1987. Parâmetros de solo para o cálculo da água disponível com base na textura do solo. Revista Brasileira de Ciência do Solo 11, 11-15.

Batjes, N.H. 1996. Development of a world data set of soil water retention properties using pedotransfer rules. Geoderma 71, 31-52. https://doi.org/10.1016/0016-7061(95)00089-5.

Bouma, J. 1989. Using soil survey data for quantitative land evaluation. Advances in Soil Science 9, 177-213. https://doi.org/10.1007/978-1-4612-3532-3_4.

Børgesen, C.D., Iversen, B.V., Jacobsen, O.H., Schaap, M.G. 2008. Pedotransfer functions estimating soil hydraulic properties using different soil parameters. Hydrological Processes 22 (11), 1630-1639. https://doi.org/10.1002/hyp.6731.

Brady, N.C. 1984. The nature and properties of soils. MacMillan Publishing Company. New York.

Dijkerman, J.C. 1988. An Ustult-Aquult-Tropept Catena in Sierra Leone, West Africa, II. Land Qualities and Land. Geoderma 42, 29-49. https://doi.org/10.1016/0016-7061(88)90021-3.

Hutson, J.L., Cass, A. 1987. A retentivity function for use in soil-water simulation models. Journal of Soil Science 38 (1), 105-113. https://doi.org/10.1111/j.1365-2389.1987.tb02128.x.

ICONA. 1986. Proyecto LUCDEME (Lucha contra la Desertificacion del Mediterraneo). Mapa de suelos, escala 1:100.000. ICONA - Ministerio de Agricultura, Pesca y Alimentación, Madrid.

Klute, A. 1986. Water retention: Laboratory methods. In: A. Klute (Ed.), Methods of Soil Analysis. Part 1: Physical and Mineralogical Methods. Agranomy Monograph 9, ASA, Madison, WI, pp. 635-662. https://doi.org/10.2136/sssabookser5.1.2ed.c26.

Kreye, P., Meon, G. 2016. Subgrid spatial variability of soil hydraulic functions for hydrological modelling. Hydrology and Earth System Sciences 20, 2557-2571. https://doi.org/10.5194/ hess-20-2557-2016. 
Lal, R. 1979. Physical properties and moisture retention characteristics of some Nigerian soils. Geoderma 21, 209-223. https://doi.org/10.1016/0016-7061(78)90028-9.

Lal, R., Mahboubi, A.A., Fausey, N.R. 1994. Long-term tillage and rotation effects on properties of a central Ohio soil. Soil Science Society of America Journal 58, 517-522. https://doi. org/10.2136/sssaj1994.03615995005800020038x.

Martínez Fernández, J. 1996. Variabilidad espacial de las propiedades físicas e hídricas de los suelos en medio semiárido mediterráneo. Tesis Doctoral, Universidad de Murcia, $191 \mathrm{pp}$.

Malik, R.S., Butter, B.S., Analauf, R., Richter, J. 1987. Water penetration into soils with different textures and initial soil contents. Soil Science 144 (6), 389-393. https://doi. org/10.1097/00010694-198712000-00001.

Masutti, M.M. 1997. Caracterização da água disponível a partir de parâmetros físico-hídricos em solos da zona da mata do Estado de Pernambuco. Tesis Doctoral, Universidade Federal Rural de Pernambuco, 69 pp., Recife. (Tesis Doctoral)

Nelson, D.W., Sommers, L.E. 1982. Total Carbon Organic Carbon and Organic Matter. In: A.L. Page, R.H. Miller, D.R. Keeny (Eds.), Methods of Soil Analysis, Part 2-Chemical and Microbiological Properties, second ed., 9, Part 2. Agronomy Monograph, Madison, WI, pp. 539-579.

Nemes, A., Rawls, W.J., Pachepsky, Y.A. 2006. Use of the Nonparametric Nearest Neighbor Approach to Estimate Soil Hydraulic Properties. Soil Science Society of America Journal 70 (2), 327-336. https://doi.org/10.2136/sssaj2005.0128.

Patil, N.G., Singh, S.K. 2016. Pedotransfer Functions for Estimating Soil Hydraulic Properties: A Review. Pedosphere 26 (4), 417-430. https://doi.org/10.1016/S1002-0160 (15)60054-6.

Peraza, J.E.S. 2003. Retenção de água e pedofunções para solos do Rio Grande do Sul. Tesis Doctoral, Universidade Federal de Santa Maria, 118 pp., Santa Maria.

Pérez Cutillas, P. 2013. Modelización de propiedades físicas del suelo a escala regional. Casos de estudios en el Sureste Ibérico. Tesis Doctoral, Universidad de Murcia, ISBN: 978-84-6970660-2.

Pérez Cutillas, P., Barberá, G.G., Conesa García, C. 2015. Estimación de la humedad del suelo a niveles de capacidad de campo y punto de marchitez mediante modelos predictivos a escala regional. Boletín de la Asociación de Geógrafos Españoles 68, 523-529.

Pérez Cutillas, P., Barberá, G.G., Conesa García, C. 2017. Efectos de las variables ambientales en la estimación de materia orgánica del suelo a escala regional. Boletín de la Asociación de Geógrafos Españoles 75, 175-191.

Pidgeon, J.D. 1972. The measurement and prediction of available water capacity of Ferrallitic soils in Uganda. Journal Soil Science, 23, 431-441. https://doi.org/10.1111/j.1365-2389.1972. tb01674.x.

Pribyl, D.W. 2010. A critical review of the conventional SOC to SOM conversion factor. Geoderma 156, 75-83. https://doi.org/10.1016/j.geoderma.2010.02.003.

Rawls, W.J., Brakensiek, D.L., Saxton, K.E. 1982.Estimation of soil water properties. Transactions of the ASAE 108, 1316-1320. https://doi.org/10.13031/2013.33720.

Rawls, W.J., Pachepsky, Y.A., Ritchie, J.E., Sobecki, T.M., Bloodworth, H, 2003. Effect of soil organic carbon on soil water retention. Geoderma 116, 61-76. https://doi.org/10.1016/S00167061(03)00094-6.

Rawls, W.J., Nemes, A., Pachepskl, Y. 2004. Effect of soil organic carbon on soil hydraulic properties. Developments in soil science 30. https://doi.org/10.1016/S0166-2481(04)30006-1.

Richards, L.A. 1947. Pressure membrane apparatus: construction and use. Agricultural Engineering 28, 451-454.

Santanello, J., Peters-Lidard, C., Garcia, M., Mocko, D., Tischler, M., Moran, M., Thomas, D. 2007. Using remotely sensed estimates of soil moisture to infer spatially distributed soil 
hydraulic properties. Remote Sensing of Environment 110, 79-97. https://doi.org/10.1016/j. rse.2007.02.007.

Schaap, M.G., Leij, F.J., Van Genuchten, M.Th. 2001. Rosetta: A computer program for estimating soil hydraulic parameters with hierarchical pedotransfer functions. Journal of Hydrology, 251 (3-4), 163-176. https://doi.org/10.1016/S0022-1694(01)00466-8.

Schuh, W.M., Cline, R.L. 1990. Effect of soil properties on unsaturated hydraulic conductivity pore- interaction factors. Soil Science Society of America Journal 54 (6), 1509-1519. https:// doi.org/10.2136/sssaj1990.03615995005400060001.x.

Šimunek, J., Van Genuchten, M.Th., Šejna, M. 2008. Development and applications of the HYDRUS and STANMOD software packages and related codes. Vadose Zone Journal 7, 587-600. https://doi.org/10.2136/vzj2007.0077.

Twarakavi, N.K.C, Šimunek, J., Schaap, M.G. 2010. Can texture-based classification optimally classify soils with respect to soil hydraulics? Water Resources Research 46 (1), W01501. https://doi.org/10.1029/2009WR007939.

Van Genuchten, M.Th. 1980. Closed-form equation for predicting the hydraulic conductivity of unsaturated soil. Soil Science Society of America Journal 44, 1147-1152. https://doi. org/10.2136/sssaj1980.03615995004400050002x.

Van Beers, W.F.J. 1980. Soils and soil properties. In: Drainage Principles and Applications.Vol. I. ILRI. Wageningen.

Wang, K., Zhang, C., Li, W. 2013. Predictive mapping of soil total nitrogen at a regional scale: A comparison between geographically weighted regression and cokriging. Applied Geography 42, 73-85. https://doi.org/10.1016/j.apgeo.2013.04.002.

Wettschereck, D., Aha, D.W., Mohri, T. 1997. A Review and Empirical Evaluation of Feature Weighting Methods for a Class of Lazy Learning Algorithms. Artificial Intelligence Review 11 (1-5), 273-314. https://doi.org/10.1023/A:1006593614256.

Wosten, J.H.M., Van Genuchten, M.T. 1988. Using texture and other soil properties to predict the unsaturated soil hydraulic functions. Soil Science Society of America Journal 52 (6), 1762 1770. https://doi.org/10.2136/sssaj1988.03615995005200060045x. 